\title{
Review Article \\ Roles of Dietary Amino Acids and Their Metabolites in Pathogenesis of Inflammatory Bowel Disease
}

\author{
Xianying Bao, ${ }^{1,2,3,4}$ Zemeng Feng, ${ }^{2,3,4,5}$ Jiming Yao, ${ }^{6}$ Tiejun Li, ${ }^{1,2,3,4,5}$ and Yulong Yin ${ }^{1,2,3,4}$ \\ ${ }^{1}$ College of Animal Science and Technology, Hunan Agriculture University, Changsha, Hunan 410128, China \\ ${ }^{2}$ Key Laboratory of Agro-Ecological Processes in Subtropical Region, Institute of Subtropical Agriculture, \\ Chinese Academy of Sciences, Hunan 410125, China \\ ${ }^{3}$ National Engineering Laboratory for Pollution Control and Waste Utilization in Livestock and Poultry Production, \\ Hunan 410125, China \\ ${ }^{4}$ Hunan Provincial Engineering Research Center for Healthy Livestock and Poultry Production, \\ Scientific Observing and Experimental Station of Animal Nutrition and Feed Science in South-Central, \\ Ministry of Agriculture, Changsha, Hunan 410125, China \\ ${ }^{5}$ Hunan Co-Innovation Center of Animal Production Safety, CICAPS, Changsha 410128, China \\ ${ }^{6}$ Guangdong Wangda Group Academician Workstation for Clean Feed Technology Research and Development in Swine, \\ Guangdong Wangda Group Co., Ltd., Guangzhou, Guangdong 510663, China
}

Correspondence should be addressed to Zemeng Feng; zemengfeng2006@163.com and Yulong Yin; yinyulong@isa.ac.cn

Received 20 September 2016; Revised 18 January 2017; Accepted 22 February 2017; Published 14 March 2017

Academic Editor: Michael Conlon

Copyright (C) 2017 Xianying Bao et al. This is an open access article distributed under the Creative Commons Attribution License, which permits unrestricted use, distribution, and reproduction in any medium, provided the original work is properly cited.

Inflammatory Bowel Disease (IBD) is a kind of chronic inflammation, which has increasing incidence and prevalence in recent years. IBD mainly divides into Crohn's disease (CD) and ulcerative colitis (UC). It is hard to cure IBD completely, and novel therapies are urgently needed. Amino acids (AAs) and their metabolites are regarded as important nutrients for humans and animals and also play an important role in IBD amelioration. In the present study, the potential protective effects of AAs and their metabolites on IBD had been summarized with the objective to provide insights into IBD moderating using dietary AAs and their metabolites as a potential adjuvant therapy.

\section{Inflammatory Bowel Disease Prevalence and Increasing Incidence}

Inflammatory bowel disease (IBD) is a kind of chronically multifactorial inflammatory disorder affecting the gastrointestinal tract [1]. It is triggered as a consequence of excessive proinflammatory cytokines production, persistent macrophage activation, and cell death induced by subsequent bacterial or/and viral infections. IBD is the major intestinal health concerns causing severe diarrhea, abdominal pain, weight loss, metabolic disorder, and malabsorption, and it mainly comprises two major forms: Crohn's disease (CD) and ulcerative colitis (UC) $[2,3]$. CD and UC have different inflammatory location in the gastrointestinal tract. $\mathrm{CD}$ affects all layers of the gastrointestinal tract and is associated with excess expression of IL-12/IL-23 and IFN- $\gamma /$ IL-17, while UC mainly occurs in colon affecting the mucosa with primarily excess production of IL-13 $[3,4]$. Currently, the incidence and prevalence of IBD are increasing with time around the world, especially the rate within elderly patients [5]. The developed countries (Europe and North America) present the highest occurrence [6]. In the West, the prevalence of IBD is 37 to 249 cases per 100,000 people for UC and from 26 to 319 cases per 100,000 people for CD [6, 7]. By contrast, Eastern Europe, Asia, and other developing countries have a lower IBD incidence [7-9]. The occurrence of UC in Asian countries is higher than that of CD [10].

The pathogenesis of IBD is complex and still unclear. Mounting evidences suggest that IBD is the consequence of abnormal immune regulation induced by genetic and/or environmental factors (e.g., diet, infection) $[1,11]$. Various inflammation mediators including reactive oxygen species 
and proinflammatory cytokines (NF- $\kappa \mathrm{B}$, cytochrome $\mathrm{c}$, and tumor necrosis factor- (TNF-)- $\alpha$ ) act as predisposing factors for chronic inflammatory diseases [12]. The typical clinical inflammation of the gastrointestinal tract leads to IBD with excessive production of proinflammatory mediators and loss of the intestinal mucosal barrier integrity. Since there is no complete cure for IBD, the therapies of IBD primarily focus on inducing or maintaining remission and promoting the expression of anti-inflammatory genes [3].

At the present, the conventional treatments of IBD such as biological therapies targeting specific cytokines or pathways and clinical medication have been improved in recent years. Mesalamine, antibiotics, and budesonide are used in patients with mild disease status, while patients with moderately severe IBD take systemic corticosteroids, immunemodulators (thiopurine analogues, azathioprine (AZA), 6mercaptopurine (6-MP), and methotrexate), and anti-TNF $\alpha$ agents (infliximab, adalimumab, and certolizumab pegol) [13]. However, proper administration selection becomes a common clinical dilemma with those different kinds of medicines. The conventional treatments in severe IBD have a short-term favorable prognosis, while there is still a challenge in the development of alternative therapies character with low-risk and long-term outcomes [14]. Besides, treatments mentioned above are proved to have limited efficacy, adverse effects, drug interactions, and potential toxicity $[15,16]$. The use of AZA and 6-MP in IBD patients leads to serious adverse drug reactions such as hepatotoxicity, pancreatitis, and gastrointestinal disturbances [17]. Immunosuppressive and antiTNF therapy in IBD cause dermatological adverse effects, including skin infections, drug hypersensitivity, psoriasis, eczema, and nonmelanomatous skin cancer $[18,19]$.

In most cases, patients suffering IBD usually face long duration which becomes a considerable economic burden. With the development of medical and life science, a large number of new strategies are provided to treat IBD. Functional nutrients have aroused growing interest, which help prevent or remit malnutrition, moderate the mucosal immune response, and benefit intestinal homeostasis [2022]. Essential nutrient has the potential to ameliorate restore redox balance and inflammation in the gastrointestinal tract showing the possibility of nutrients in IBD treatment [3]. Part of the nutrients that benefit the management of IBD had been listed in Table 1.

\section{Amino Acids: Application in Inflammatory Bowel Disease Therapies}

Among IBD benefit nutrients, amino acids (AAs) act as the key regulatory factor in metabolic pathways controlling and have important effects on keeping the intestinal health. AAs are considered as the building blocks for protein synthesis and also play major roles in other functions, such as cell signaling, gene expression, intracellular protein turnover, maintenance, reproduction, oxidative stress, and immunity $[46,47]$. Systemic inflammation can cause malnutrition symptoms and general glutamine (Gln) deprivation which is associated with depression, muscle loss, and emotional fatigue [48]. Both UC and CD disturb AAs metabolism in serum and plasma by increasing levels of isoleucine (Ile) (and its first degradation product 3-methyl-2-oxovalerate), methionine (Met), lysine, glycine (Gly), arginine (Arg), and proline (Pro), while decreasing levels of valine, tyrosine, and serine [49]. Some of the increased AAs were also reported to be increased in fecal extracts [50], while Ile and leucine (Leu) have apparently low concentrations in colonic mucosa of active IBD [51]. Met is an essential amino acid and a precursor of homocysteine, a metabolite shown highly elevated in both plasma and colonic mucosa from IBD patients [52].

AAs also have trophic and cytoprotective effects on health in humans and animals $[53,54]$. $\mathrm{T}$ cells are regarded as central effectors of the adaptive immune system. T helper (Th) cells (Th1, Th2, and Th 17 cells) differentiate from native $\mathrm{CD} 4^{+} \mathrm{T}$ cells and are involved in the pathogenesis of several inflammatory immune-mediated disorders such as producing different cytokines in immune responses [55]. CD is a Thl-type T cell-mediated inflammation while UC is a Th2-type T cell-mediated inflammation [4]. AAs directly serve as a fuel source for $\mathrm{T}$ cells and are considered to have influence on shaping $\mathrm{T}$ cell-mediated immune responses [56]. Additionally, the signaling central integrator of environmental stimuli for the regulation of $\mathrm{T}$ cell activation and differentiation is mammalian target of rapamycin (mTOR) $[57,58]$. mTOR have two distinct protein complexes, mTOR complex 1 (mTORC1) and mTOR complex 2 (mTORC2). In T cells, AAs work as signaling molecules with mTORC1 acting as a key mediator. AAs regulate the intracellular localization and activation of mTORC1 by the lysosome-based signaling system composed of Ras-related GTPases (Rags) and Regulator v-ATPase, GAP activity towards Rags, and folliculin complexes $[59,60]$. AAs could protect whole body and muscle from protein loss via mTOR activation and downstream signaling to protein synthesis through mTORCl in the acute phase of inflammation [61, 62]. Leu-enriched diet accelerated recovery from muscle damage by alleviating excessive expression of proinflammatory cytokine and preventing invasion of inflammatory cells into muscle [63]. Otherwise, general controlled nonrepressed (GCN2) kinase is a key orchestrator of the integrated stress response which senses AAs depletion. Acute AAs starvation in mice protects the symptoms of colitis, limits Th17 cells, and suppressed IBD via a GCN2dependent mechanism, providing another mechanism of AAs in regulating IBD [64].

In conclusion, growing evidence shows that the antiinflammatory activities of tryptophan (Trp), Gln, Met, cysteine (Cys), and Arg have been well established, suggesting a therapeutic role of AAs in IBD, which were listed in Table 2. It is necessary to illustrate the biological activity of specific immunomodulatory AAs in IBD.

2.1. Tryptophan. Trp is an essential AA for human and animals and plays an important role in inflammatory regulation beyond building block for proteins synthesis [65]. The serious Trp concentration shows a highly inverse correlation with disease activity in IBD patients [66]. Dietary supplementation of Trp can reduce IBD through its immune-regulatory metabolites $[35,36]$. In a porcine model of dextran-sodium sulfate- (DSS-) induced colitis, Trp administration at $80 \%$ of 


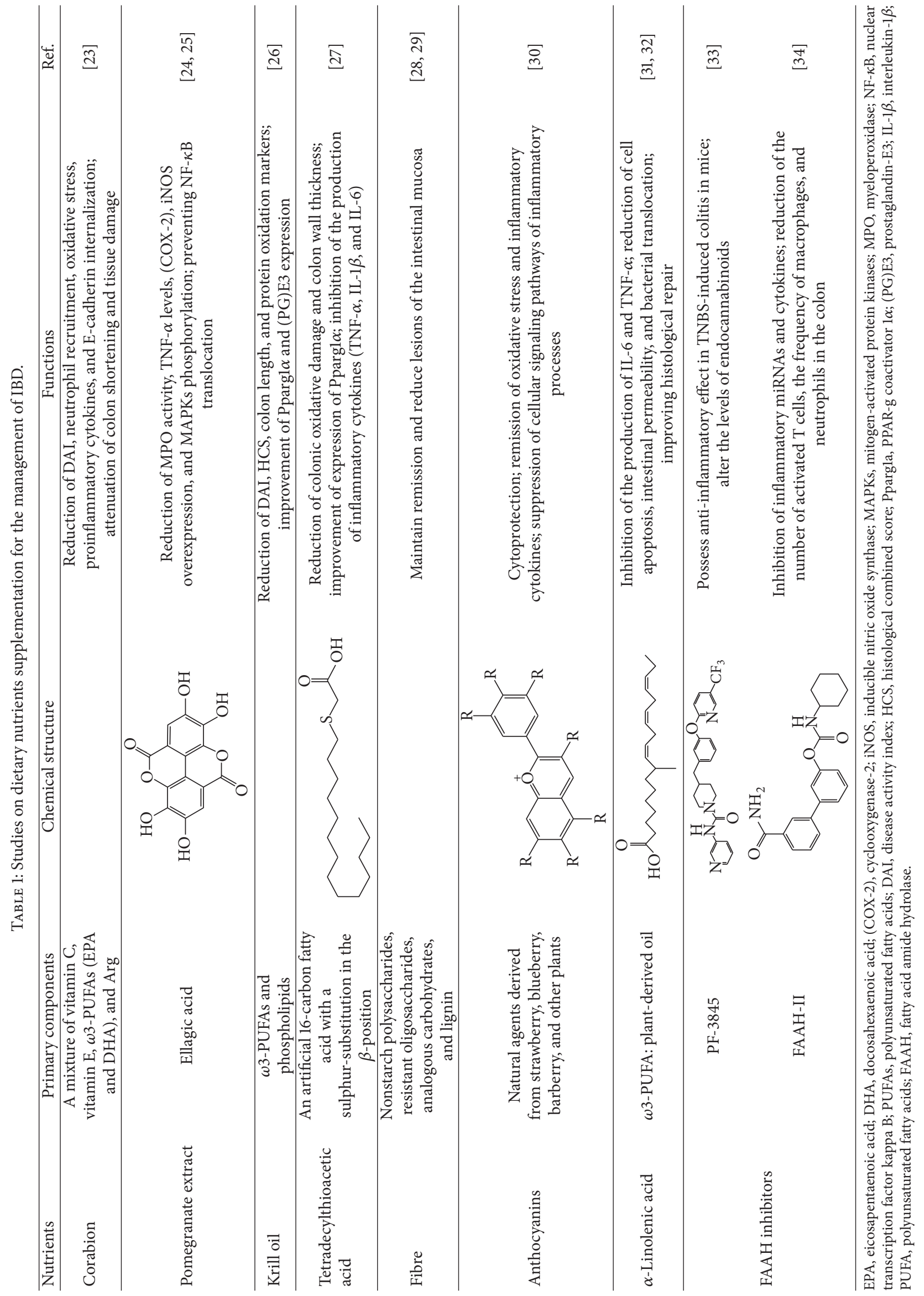


TABLE 2: Application of partial AAs in inflammatory bowel disease therapies.

\begin{tabular}{|c|c|c|c|c|c|}
\hline AAs & Dose & $\begin{array}{l}\text { Administration } \\
\text { method }\end{array}$ & Models & Major functions and effects & Ref \\
\hline Tryptophan & $88 \mathrm{mg} / \mathrm{kg} \cdot \mathrm{BW} \cdot$ day & $\begin{array}{l}\text { Intragastric } \\
\text { infusion }\end{array}$ & Piglets & $\begin{array}{l}\text { Amelioration of clinical symptoms; reduction of gut } \\
\text { permeability and cell apoptosis; inhibition of the } \\
\text { production of inflammatory cytokines (TNF- } \alpha \text {, IL- } 6 \text {, } \\
\text { IFN- } \gamma \text {, IL-12p40, IL-1 } \beta \text {, and ICAM-1) }\end{array}$ & {$[35]$} \\
\hline Melatonin & $20 \mathrm{mg} / \mathrm{kg} \cdot \mathrm{BW} \cdot$ day & $\begin{array}{l}\text { Intragastric } \\
\text { infusion }\end{array}$ & Rats & $\begin{array}{l}\text { Antioxidant; inhibition of the production of } \\
\text { inflammatory cytokines (TNF- } \alpha \text {, COX-2, SOD, and } \\
\text { NF- } \kappa \mathrm{B} \text { ); accelerating healing of gastric ulcer }\end{array}$ & {$[36]$} \\
\hline Glutamine & $\begin{array}{l}25 \% \text { of the total } \\
\text { nitrogen }\end{array}$ & Dietary & Mice & $\begin{array}{l}\text { Anti-inflammation; reduction of expression of } \\
\text { PSGL-1, LFA-1, and CCR9 by Th cells }\end{array}$ & {$[37]$} \\
\hline Glutamate & $12 \mu \mathrm{g} \mathrm{Glu} / 0.3 \mu \mathrm{L}$ saline & Microinjection & Rats & $\begin{array}{l}\text { Neurotransmitter; inhibition of T-cell response and } \\
\text { inflammation }\end{array}$ & {$[38]$} \\
\hline Methionine & $0.12 \% \mathrm{~L}-\mathrm{Met}$ & Dietary & Piglets & Protection of the small-intestinal mucosa & {$[39]$} \\
\hline Cysteine & $144 \mathrm{mg} / \mathrm{kg} \cdot \mathrm{BW} \cdot$ day & $\begin{array}{l}\text { Intragastric } \\
\text { infusion }\end{array}$ & Piglets & $\begin{array}{l}\text { Reduction of intestinal permeability and cell } \\
\text { apoptosis; inhibition of the local expression of } \\
\text { inflammatory mediators (IL-6, TNF- } \alpha \text {, IL-12p40, } \\
\text { and IL-1 } \beta \text { ) }\end{array}$ & {$[40$} \\
\hline Histidine & Not mentioned & Dietary & Mice & $\begin{array}{l}\text { Reduction of histologic damage, colon weight, IL- } 6 \text {, } \\
\text { and TNF- } \alpha \text { production; inhibition of NF- } \kappa \text { B }\end{array}$ & {$[41]$} \\
\hline Arginine & $1 \%(\mathrm{wt} / \mathrm{vol}$ ) solution & Drinking water & Mice & $\begin{array}{l}\text { Improvement of the clinical parameters and body } \\
\text { weight loss; reduction of the colonic permeability; } \\
\text { reduction of the proinflammatory cytokine and } \\
\text { chemokine expression }\end{array}$ & {$[42]$} \\
\hline Glycine & 5\% Gly & Dietary & Rats & $\begin{array}{l}\text { Diarrhea amelioration; prevention of the increases of } \\
\text { IL- } 1 \beta \text { and TNF- } \alpha\end{array}$ & {$[43]$} \\
\hline \multirow{2}{*}{ Taurine } & $30 \mathrm{mM}$ & $\begin{array}{c}\text { Rectal } \\
\text { administration }\end{array}$ & Rats & Anti-inflammation; inhibiting NF- $\kappa \mathrm{B}$ activity & {$[44$} \\
\hline & $2 \%$ & Drinking water & Mice & $\begin{array}{l}\text { Inhibitory effects on the secretion of MIP-2; } \\
\text { cytoprotective functions on the epithelial barrier }\end{array}$ & {$[45]$} \\
\hline
\end{tabular}

TNF- $\alpha$, tumor necrosis factor- $\alpha$; IL, interleukin; IFN- $\gamma$, interferon- $\gamma$; ICAM-1, intracellular adhesion molecule-1; PSGL-1, P-selectin glycoprotein ligand-1; LFA-1, leukocyte function-associated antigen-1; CCR9, C-C chemokine receptor type 9; MIP-2, macrophage inflammatory protein 2.

the daily recommended intake could ameliorate colitis clinical symptoms, improve histological parameters and intestinal permeability, reduce the expression of proinflammatory cytokines, and increase the expression of proapoptotic genes, which is important for maintaining gut homeostasis [35]. Trp presents strong anti-inflammation activity by triggering calcium-sensing receptor (CaSR) activation in intestine [67], which is a sensing receptor for dietary nutrients in the gastrointestinal tract to maintain mucosal immune homeostasis. Trp treatment allosterically activate CaSR which significantly reduces TNF- $\alpha$-induced interleukin- (IL-) 8 secretion indicating a novel therapy in intestinal inflammation [67].

In addition, Trp exerts anti-inflammatory function via the metabolites including serotonin (5-hydroxytryptamine, 5-HT) and melatonin (MT). 5-HT is an important compound derived from Trp which serves as a neurotransmitter and inhibiter of the production of inflammatory cytokines and superoxide [46]. MT is abundant in gastrointestinal tract $[68,69]$ and has a positive impact on IBD with no or negligible side effects due to regulation of macrophage activity, reduction of cell migration and myeloperoxidase activity, and inhibition of NF- $\kappa \mathrm{B}$ and TNF- $\alpha$ expression $[36,68,70]$. MT added to omeprazole treatment obviously accelerates chronic gastroduodenal ulcers over the obtained with omeprazole alone [71]. Additionally, in mice with DSS-induced colitis, MT exerts anti-inflammatory effects by alleviating the severity of mucosal injury and recovering the expression of IL-6, IL-17, and adiponectin [72].

2.2. Glutamine and Glutamate. As an abundant AA in the blood and tissues, Gln is mostly used as nitrogen source and/or alternative energy fuel [73]. In various clinical situations, appropriate exogenous Gln supply is safe and can beneficially contribute to diminishing risks of high-dose chemotherapy and radiation [74]. It has been additionally implicated as an immunomodulatory nutrient [75] and has pharmacological function in the IBD treatment [76]. Gln plays a key role in maintaining the integrity of the intestinal mucosa and has been shown to reduce inflammation and relieve CD [77]. In an UC mouse model, dietary Gln supplementation combined with dietary fiber and oligosaccharide has suppressive effects on mucosal damage [78]. A Gln diet replacing 25\% of the total nitrogen decreases the expression of chemokine and endothelial adhesion molecules via suppression of $\mathrm{T}$ cell migration in mice [37]. These experimental data suggest Gln as a potential nutrient in protecting intestinal integrity and modulating immunity. 
Glutamate (Glu) is produced from Gln with the catalysis of glutaminase and generally plays roles in protein synthesis and energy metabolism. Dietary Glu can also function as a signal to regulate the gastrointestinal tract via the gut-brain axis [9]. As a precursor of glutathione (GSH), Arg and Pro, Glu is of critical importance in intestinal metabolism and physiology [53]. Microinjection of Glu into the hypothalamic paraventricular nucleus in UC rats significantly increases the cell proliferation and antioxidant levels and decreases apoptosis and the expression of proinflammatory factors in the colonic mucosa [38]. Poly- $\gamma$-glutamate (P-Glu) significantly reduced histopathological evidence of injury, attenuated DSS-induced blood vessel densities, and attenuated DSSinduced expression of VEGF-A and its receptor in C57BL/6 mouse colitis model. P-Glu has potential application in conditions marked by inflammatory-driven angiogenesis and mucosal inflammation [79]. These findings above indicate that dietary supplementation of Gln and Glu is of functional and nutritional importance in intestinal mucosal growth and gut inflammation.

2.3. Sulfur Amino Acids. Sulfur amino acids (SAAs) mainly contain Met, Cys, and cystine. SAAs metabolism mainly takes place in the gastrointestinal tract. Dietary deficiency of SAAs will suppress intestinal mucosal growth, reduce intestinal epithelial cell proliferation, and increase intestinal oxidant stress in piglets [80].

As essential AA, Met has been considered as the first and second or third limiting AA in poultry and nursery pigs, respectively. Piglets fed the diet supplemented with Met present increased growth performance and exhibited improved integrity and barrier function of the smallintestinal mucosa [39]. Dietary supplementation with Met metabolites also can affect the susceptibility to colitis, reduce inflammation and tissue injury, and decrease the expression of multiple inflammatory genes in mice [81]. It is also interesting that Met (twice NRC recommendation) combined with fish oil (2.5\%) can enhance immune response in IBD challenged broiler chickens which may be a novel treatment in IBD therapy for poultry [82].

Cys is a nonessential AA playing roles in protein metabolism and is regarded as the key factor in the synthesis of GSH. Dietary supplementation with $\mathrm{N}$-acetyl-L-cysteine improves the clinical symptoms and decreases the chemokines without any side effects [83]. Cys administration can attenuate DSS-induced weight loss and intestinal permeability, decrease the expression of proinflammatory cytokines, and restore susceptibility of activated immune cells to apoptosis, indicating Cys supplementation as a novel therapy for IBD [40]. In addition, $\gamma$-glutamyl cysteine treatment can ameliorate DSS-induced clinical signs and histological damage via activating CaSR [84].

Besides, GSH, taurine (Tau), and hydrogen sulfide $\left(\mathrm{H}_{2} \mathrm{~S}\right)$, the products of catabolism of SAAs, play major roles in antiinflammation and antioxidant system [46]. Tau is regarded as an antioxidant and membrane stabilizer against oxidative stress and inflammation by inhibiting chemokine secretion from intestinal cells $[85,86]$. Moreover, the cellular metabolite taurine chloramine of Tau in the rectal shows anti-inflammatory property on IBD via inhibition on NF$\kappa \mathrm{B}$ activity $[44,87]$. Tau treatment exerts beneficial effects in rats with 2,4,6-trinitrobenzene sulphonic acid- (TNBS-) induced colitis with decreasing inflammatory reactions and apoptosis [88]. $\mathrm{H}_{2} \mathrm{~S}$ is a signaling molecule and a gaseous mediator that exhibits several anti-inflammatory activities and contributes to mucosal protection [89-91]. One of the possible mechanisms of $\mathrm{H}_{2} \mathrm{~S}$ in the resolution of IBD is proved to be mediated via stabilization of hypoxia-inducible factor-1 $\alpha[92]$.

2.4. Arginine. Arg is a semiessential AA that has protective effects against oxidative stress. As the substrate for nitric oxide (NO) synthesis, amino acid Arg is reported to be therapeutic in wound healing and has potent anti-inflammatory properties as a mediator of autoimmune diseases [93-96]. Otherwise, exogenous Arg is associated with antiapoptotic effects on the rat intestine and useful in the treatment of intestinal ischemia/reperfusion injury [97]. Dietary supplementation with Arg can improve the immune status of humans and animals and has the potential to be used to supplement current treatments for IBD [12]. Serum Arg concentration is a useful biomarker of UC disease severity [98]. Further, in a DSS-induced fulminant colitis murine model, treatment with hepatocyte growth factor and Arg can decline associated symptoms such as pain and diarrhea [99]. Arg is absorbed and transferred by cationic AA transporters (CAT) in intestine. DSS-induced inflammation reduced the expression of CAT2 in colonic and Arg uptake with body weight loss, reducing colonic permeability. Supplementation with Arg markedly attenuates the clinical parameters above and reduces the expression of proinflammatory cytokine and chemokine [42]. Arg might reduce the inflammation associated with AA-induced colitis through the NF- $\kappa \mathrm{B} /$ nitric oxide pathway [100]. NO participates in nutrient metabolism and exerts protective effects against IBD including inhibition of macrophage activation and proinflammatory cytokine levels [101].

2.5. Other AAs. Besides the functional AAs above, other AAs have been reported to possess anti-inflammation functions to some extent. In addition to acting as an important precursor for the biosynthesis of GSH, Gly is proved to ameliorate diarrhea and body weight loss in TNBS induced colitis in the rats, indicating that Gly may be a useful immunomodulating nutrient for the treatment of IBD [43]. Histidine has proven to be a novel therapeutic agent for $\mathrm{CD}$ by inhibition of $\mathrm{NF}-\kappa \mathrm{B}$ activation, downregulating proinflammatory cytokine production in IL10 ${ }^{-/-}$mice [41]. Ergothioneine (EGT) is a natural water-soluble amino acid which can be derived from mushroom or synthesized by nonyeast fungi $[102,103]$. In ultraviolet-B-irradiated mice, the administration of EGT inhibited the UV-B-induced inflammatory responses and DNA halogenation, showing the modulatory effects of EGT in inflammation [103].

\section{Future Perspectives and Challenge}

Lacking of effective medical therapies for IBD makes it of utmost importance to find alternative therapeutic strategies 
[3]. AAs can relieve intestinal inflammation through regulation of proinflammatory cytokines suggesting a possible approach to IBD treatment. However, further investigations and clinical studies are needed to fully understand the therapeutic mechanism and potential of AAs in preventing inflammation in both humans and animals.

\section{Disclosure}

The funding sources played no role in the study design, data collection and interpretation, or the decision to submit the work for publication.

\section{Conflicts of Interest}

The authors declare that they have no conflicts of interest.

\section{Acknowledgments}

This project was supported by the Chinese Academy of Sciences STS Project (KFJ-SW-STS-173), the National Basic Research Program of China (973 Program) (2013CB127301), and the National "948" Project from the Ministry of Agriculture of China (2015Z74).

\section{References}

[1] D. Corridoni, K. O. Arseneau, and F. Cominelli, "Inflammatory bowel disease," Immunology Letters, vol. 161, no. 2, pp. 231-235, 2014.

[2] M. E. Himmel, G. Hardenberg, C. A. Piccirillo, T. S. Steiner, and M. K. Levings, "The role of T-regulatory cells and Toll-like receptors in the pathogenesis of human inflammatory bowel disease," Immunology, vol. 125, no. 2, pp. 145-153, 2008.

[3] H. Zhang, C.-A. A. Hu, J. Kovacs-Nolan, and Y. Mine, "Bioactive dietary peptides and amino acids in inflammatory bowel disease," Amino Acids, vol. 47, no. 10, pp. 2127-2141, 2015.

[4] W. Strober, I. Fuss, and P. Mannon, "The fundamental basis of inflammatory bowel disease," The Journal of Clinical Investigation, vol. 117, no. 3, pp. 514-521, 2007.

[5] S. Taleban, "Challenges in the diagnosis and management of inflammatory bowel disease in the elderly," Current Treatment Options in Gastroenterology, vol. 13, no. 3, pp. 275-286, 2015.

[6] N. A. Molodecky, I. S. Soon, D. M. Rabi et al., "Increasing incidence and prevalence of the inflammatory bowel diseases with time, based on systematic review," Gastroenterology, vol. 142, no. 1, pp. 46-54.e42, 2012.

[7] E. V. Loftus Jr., "Clinical epidemiology of inflammatory bowel disease: incidence, prevalence, and environmental influences," Gastroenterology, vol. 126, no. 6, pp. 1504-1517, 2004.

[8] S. C. Ng, W. Tang, J. Y. Ching et al., "Incidence and phenotype of inflammatory bowel disease based on results from the AsiaPacific Crohn's and colitis epidemiology study," Gastroenterology, vol. 145, no. 1, pp. 158-165.e2, 2013.

[9] B. D. Lovasz, P. A. Golovics, Z. Vegh, and P. L. Lakatos, "New trends in inflammatory bowel disease epidemiology and disease course in Eastern Europe," Digestive and Liver Disease, vol. 45, no. 4, pp. 269-276, 2013.

[10] H. Yang, Y. Li, W. Wu et al., "The incidence of inflammatory bowel disease in Northern China: A Prospective Populationbased Study," PLOS ONE, vol. 9, no. 7, Article ID e101296, 2014.
[11] C. Fiocchi, "Inflammatory bowel disease: etiology and pathogenesis," Gastroenterology, vol. 115, no. 1, pp. 182-205, 1998.

[12] A. M. Al-Drees and M. S. Khalil, "Histological and immunohistochemical effects of L-arginine and silymarin on TNBSinduced inflammatory bowel disease in rats," Histology and Histopathology, vol. 31, no. 11, pp. 1259-1270, 2016.

[13] T. Dassopoulos, S. Sultan, Y. T. Falck-Ytter, J. M. Inadomi, and S. B. Hanauer, "American gastroenterological association institute technical review on the use of thiopurines, methotrexate, and anti-TNF- $\alpha$ biologic drugs for the induction and maintenance of remission in inflammatory Crohn's disease," Gastroenterology, vol. 145, no. 6, pp. 1464-1478.e5, 2013.

[14] M. Cöeffier, R. Marion-Letellier, and P. Déchelotte, "Potential for amino acids supplementation during inflammatory bowel diseases," Inflammatory Bowel Diseases, vol. 16, no. 3, pp. 518524, 2010.

[15] S. De Silva, S. Devlin, and R. Panaccione, "Optimizing the safety of biologic therapy for IBD," Nature Reviews Gastroenterology and Hepatology, vol. 7, no. 2, pp. 93-101, 2010.

[16] R. B. Gearry, M. L. Barclay, M. J. Burt, J. A. Collett, and B. A. Chapman, "Thiopurine drug adverse effects in a population of New Zealand patients with inflammatory bowel disease," Pharmacoepidemiology and Drug Safety, vol. 13, no. 8, pp. 563567, 2004.

[17] M. Schwab, E. Schäffeler, C. Marx et al., "Azathioprine therapy and adverse drug reactions in patients with inflammatory bowel disease: impact of thiopurine S-methyltransferase polymorphism," Pharmacogenetics, vol. 12, no. 6, pp. 429-436, 2002.

[18] G. W. Moran, A. W. K. Lim, J. L. Bailey et al., "Review article: dermatological complications of immunosuppressive and antiTNF therapy in inflammatory bowel disease," Alimentary Pharmacology and Therapeutics, vol. 38, no. 9, pp. 1002-1024, 2013.

[19] J. Torres, S. Buche, E. Delaporte, and J.-F. Colombel, "Skin side effects of inflammatory bowel disease therapy," Inflammatory Bowel Diseases, vol. 19, no. 5, pp. 1086-1098, 2013.

[20] M. G. Neuman and R. M. Nanau, "Inflammatory bowel disease: role of diet, microbiota, life style," Translational Research, vol. 160, no. 1, pp. 29-44, 2012.

[21] F. M. Ruemmele, "Role of diet in inflammatory bowel disease," Annals of Nutrition and Metabolism, vol. 68, supplement 1, pp. 33-41, 2016.

[22] R. Altomare, G. Damiano, A. Abruzzo et al., "Enteral nutrition support to treat malnutrition in inflammatory bowel disease," Nutrients, vol. 7, no. 4, pp. 2125-2133, 2015.

[23] H. Vargas Robles, A. F. Citalán Madrid, A. García Ponce et al., "Experimental colitis is attenuated by cardioprotective diet supplementation that reduces oxidative stress, inflammation, and mucosal damage," Oxidative Medicine and Cellular Longevity, vol. 2016, Article ID 8473242, 9 pages, 2016.

[24] M. A. Rosillo, M. Sánchez-Hidalgo, A. Cárdeno et al., "Dietary supplementation of an ellagic acid-enriched pomegranate extract attenuates chronic colonic inflammation in rats," Pharmacological Research, vol. 66, no. 3, pp. 235-242, 2012.

[25] T. Ismail, P. Sestili, and S. Akhtar, "Pomegranate peel and fruit extracts: a review of potential anti-inflammatory and antiinfective effects," Journal of Ethnopharmacology, vol. 143, no. 2, pp. 397-405, 2012.

[26] T. Grimstad, B. Bjørndal, D. Cacabelos et al., "Dietary supplementation of krill oil attenuates inflammation and oxidative stress in experimental ulcerative colitis in rats," Scandinavian Journal of Gastroenterology, vol. 47, no. 1, pp. 49-58, 2012. 
[27] B. Bjørndal, T. Grimstad, D. Cacabelos et al., "Tetradecylthioacetic acid attenuates inflammation and has antioxidative potential during experimental colitis in rats," Digestive Diseases and Sciences, vol. 58, no. 1, pp. 97-106, 2013.

[28] A. Pituch-Zdanowska, A. Banaszkiewicz, and P. Albrecht, "The role of dietary fibre in inflammatory bowel disease," Przeglad Gastroenterologiczny, vol. 10, no. 3, pp. 135-141, 2015.

[29] C. Wong, P. J. Harris, and L. R. Ferguson, "Potential benefits of dietary fibre intervention in inflammatory bowel disease," International Journal of Molecular Sciences, vol. 17, no. 6, article E919, 2016.

[30] H. R. Sodagari, M. H. Farzaei, R. Bahramsoltani, A. H. Abdolghaffari, M. Mahmoudi, and N. Rezaei, "Dietary anthocyanins as a complementary medicinal approach for management of inflammatory bowel disease," Expert Review of Gastroenterology and Hepatology, vol. 9, no. 6, pp. 807-820, 2015.

[31] R. Reifen, A. Karlinsky, A. H. Stark, Z. Berkovich, and A. Nyska, " $\alpha$-Linolenic acid (ALA) is an anti-inflammatory agent in inflammatory bowel disease," Journal of Nutritional Biochemistry, vol. 26, no. 12, pp. 1632-1640, 2015.

[32] S. V. Generoso, N. M. Rodrigues, L. M. Trindade et al., "Dietary supplementation with omega-3 fatty acid attenuates 5fluorouracil induced mucositis in mice," Lipids in Health and Disease, vol. 14, no. 1, article 54, 2015.

[33] M. Sałaga, A. Mokrowiecka, P. K. Zakrzewski et al., "Experimental colitis in mice is attenuated by changes in the levels of endocannabinoid metabolites induced by selective inhibition of fatty acid amide hydrolase (FAAH)," Journal of Crohn's and Colitis, vol. 8, no. 9, pp. 998-1009, 2014.

[34] H. Shamran, N. P. Singh, E. E. Zumbrun et al., "Fatty acid amide hydrolase (FAAH) blockade ameliorates experimental colitis by altering microRNA expression and suppressing inflammation," Brain, Behavior, and Immunity, vol. 59, pp. 10-20, 2016.

[35] C. J. Kim, J. A. Kovacs-Nolan, C. Yang, T. Archbold, M. Z. Fan, and Y. Mine, "L-Tryptophan exhibits therapeutic function in a porcine model of dextran sodium sulfate (DSS)-induced colitis," Journal of Nutritional Biochemistry, vol. 21, no. 6, pp. 468-475, 2010.

[36] P. C. Konturek, G. Burnat, T. Brzozowski, Y. Zopf, and S. J. Konturek, "Tryptophan free diet delays healing of chronic gastric ulcers in rat," Journal of Physiology and Pharmacology, vol. 59, no. 2, pp. 53-65, 2008.

[37] Y.-C. Hou, J.-M. Wu, M.-Y. Wang et al., "Glutamine supplementation attenuates expressions of adhesion molecules and chemokine receptors on $\mathrm{T}$ cells in a murine model of acute colitis," Mediators of Inflammation, vol. 2014, Article ID 837107, 14 pages, 2014.

[38] T.-T. Li, J.-F. Zhang, S.-J. Fei et al., "Glutamate microinjection into the hypothalamic paraventricular nucleus attenuates ulcerative colitis in rats," Acta Pharmacologica Sinica, vol. 35, no. 2, pp. 185-194, 2014.

[39] Y. Chen, D. Li, Z. Dai et al., "L-Methionine supplementation maintains the integrity and barrier function of the smallintestinal mucosa in post-weaning piglets," Amino Acids, vol. 46, no. 4, pp. 1131-1142, 2014.

[40] C. J. Kim, J. Kovacs-Nolan, C. Yang, T. Archbold, M. Z. Fan, and Y. Mine, "L-cysteine supplementation attenuates local inflammation and restores gut homeostasis in a porcine model of colitis," Biochimica et Biophysica Acta - General Subjects, vol. 1790, no. 10, pp. 1161-1169, 2009.

[41] A. Andou, T. Hisamatsu, S. Okamoto et al., "Dietary histidine ameliorates murine colitis by inhibition of proinflammatory cytokine production from macrophages," Gastroenterology, vol. 136, no. 2, pp. 564-574.e2, 2009.

[42] L. A. Coburn, X. Gong, K. Singh et al., "L-arginine supplementation improves responses to injury and inflammation in dextran sulfate sodium colitis," PLoS ONE, vol. 7, no. 3, Article ID e33546, 2012.

[43] I. Tsune, K. Ikejima, M. Hirose et al., "Dietary glycine prevents chemical-induced experimental colitis in the rat," Gastroenterology, vol. 125, no. 3, pp. 775-785, 2003.

[44] H. Kim, H. Jeon, H. Kong et al., "A molecular mechanism for the anti-inflammatory effect of taurine-conjugated 5aminosalicylic acid in inflamed colon," Molecular Pharmacology, vol. 69, no. 4, pp. 1405-1412, 2006.

[45] Z. Zhao, H. Satsu, M. Fujisawa et al., "Attenuation by dietary taurine of dextran sulfate sodium-induced colitis in mice and of THP-1-induced damage to intestinal Caco-2 cell monolayers," Amino Acids, vol. 35, no. 1, pp. 217-224, 2008.

[46] G. Wu, "Amino acids: metabolism, functions, and nutrition," Amino Acids, vol. 37, no. 1, pp. 1-17, 2009.

[47] J. R. Terrill, M. N. Duong, R. Turner et al., "Levels of inflammation and oxidative stress, and a role for taurine in dystropathology of the golden retriever muscular dystrophy dog model for duchenne muscular dystrophy," Redox Biology, vol. 9, pp. 276-286, 2016.

[48] M. Schlemmer, U. Suchner, B. Schäpers et al., "Is glutamine deficiency the link between inflammation, malnutrition, and fatigue in cancer patients?" Clinical Nutrition, vol. 34, no. 6, pp. 1258-1265, 2015.

[49] R. Schicho, R. Shaykhutdinov, J. Ngo et al., "Quantitative metabolomic profiling of serum, plasma, and urine by $1 \mathrm{H}$ NMR spectroscopy discriminates between patients with inflammatory bowel disease and healthy individuals," Journal of Proteome Research, vol. 11, no. 6, pp. 3344-3357, 2012.

[50] J. R. Marchesi, E. Holmes, F. Khan et al., "Rapid and noninvasive metabonomic characterization of inflammatory bowel disease," Journal of Proteome Research, vol. 6, no. 2, pp. 546-551, 2007.

[51] K. Balasubramanian, S. Kumar, R. R. Singh et al., "Metabolism of the colonic mucosa in patients with inflammatory bowel diseases: an in vitro proton magnetic resonance spectroscopy study," Magnetic Resonance Imaging, vol. 27, no. 1, pp. 79-86, 2009.

[52] I. Morgenstern, M. T. M. Raijmakers, W. H. M. Peters, H. Hoensch, and W. Kirch, "Homocysteine, cysteine, and glutathione in human colonic mucosa: elevated levels of homocysteine in patients with inflammatory bowel disease," Digestive Diseases and Sciences, vol. 48, no. 10, pp. 2083-2090, 2003.

[53] W. W. Wang, S. Y. Qiao, and D. F. Li, "Amino acids and gut function," Amino Acids, vol. 37, no. 1, pp. 105-110, 2009.

[54] X. Liu, M. Beaumont, F. Walker et al., "Beneficial effects of an amino acid mixture on colonic mucosal healing in rats," Inflammatory Bowel Diseases, vol. 19, no. 13, pp. 2895-2905, 2013.

[55] L. Cosmi, L. Maggi, V. Santarlasci, F. Liotta, and F. Annunziato, "T helper cells plasticity in inflammation," Cytometry Part A, vol. 85, no. 1, pp. 36-42, 2014.

[56] M. C. Poffenberger and R. G. Jones, "Amino acids fuel T cellmediated inflammation," Immunity, vol. 40, no. 5, pp. 635-637, 2014.

[57] K. N. Pollizzi and J. D. Powell, "Regulation of T cells by mTOR: the known knowns and the known unknowns," Trends in Immunology, vol. 36, no. 1, pp. 13-20, 2015. 
[58] H. Chi, "Regulation and function of mTOR signalling in T cell fate decisions," Nature Reviews Immunology, vol. 12, no. 5, pp. 325-338, 2012.

[59] L. Bar-Peled and D. M. Sabatini, "Regulation of mTORC1 by amino acids," Trends in Cell Biology, vol. 24, no. 7, pp. 400-406, 2014.

[60] P. D. Pezze, S. Ruf, A. G. Sonntag et al., "A systems study reveals concurrent activation of AMPK and mTOR by amino acids," Nature Communications, vol. 7, article 13254, 2016.

[61] N. Rittig, E. Bach, H. H. Thomsen et al., "Amino acid supplementation is anabolic during the acute phase of endotoxininduced inflammation: a human randomized crossover trial," Clinical Nutrition, vol. 35, no. 2, pp. 322-330, 2016.

[62] S. J. Crozier, S. R. Kimball, S. W. Emmert, J. C. Anthony, and L. S. Jefferson, "Oral leucine administration stimulates protein synthesis in rat skeletal muscle," Journal of Nutrition, vol. 135, no. 3, pp. 376-382, 2005.

[63] H. Kato, K. Miura, S. Nakano, K. Suzuki, M. Bannai, and Y. Inoue, "Leucine-enriched essential amino acids attenuate inflammation in rat muscle and enhance muscle repair after eccentric contraction," Amino Acids, vol. 48, no. 9, pp. 21452155, 2016.

[64] R. Ravindran, J. Loebbermann, H. I. Nakaya et al., “The amino acid sensor GCN2 controls gut inflammation by inhibiting inflammasome activation," Nature, vol. 531, no. 7595, pp. 523$527,2016$.

[65] K. Yao, J. Fang, Y.-L. Yin, Z.-M. Feng, Z.-R. Tang, and G. $\mathrm{Wu}$, "Tryptophan metabolism in animals: important roles in nutrition and health," Frontiers in Bioscience (Scholar Edition), vol. 3, no. 1, pp. 286-297, 2011.

[66] T. Hisamatsu, S. Okamoto, M. Hashimoto et al., "Novel, objective, multivariate biomarkers composed of plasma amino acid profiles for the diagnosis and assessment of inflammatory bowel disease," PLoS ONE, vol. 7, no. 1, Article ID e31131, 2012.

[67] Y. Mine and H. Zhang, "Calcium-sensing receptor (CaSR)mediated anti-inflammatory effects of L-amino acids in intestinal epithelial cells," Journal of Agricultural and Food Chemistry, vol. 63, no. 45, pp. 9987-9995, 2015.

[68] S. Mozaffari and M. Abdollahi, "Melatonin, a promising supplement in inflammatory bowel disease: a comprehensive review of evidences," Current Pharmaceutical Design, vol. 17, no. 38, pp. 4372-4378, 2011.

[69] F. Söderquist, P. M. Hellström, and J. L. Cunningham, "Human gastroenteropancreatic expression of melatonin and its receptors MT1 and MT2," PLoS ONE, vol. 10, no. 3, Article ID e0120195, 2015.

[70] H. G. Sayyed, R. J. Jaumdally, N. K. Idriss, D. A. El Sers, and A. Blann, "The effect of melatonin on plasma markers of inflammation and on expression of nuclear factor-kappa beta in acetic acid-induced colitis in the rat," Digestive Diseases and Sciences, vol. 58, no. 11, pp. 3156-3164, 2013.

[71] K. Celinski, P. C. Konturek, S. J. Konturek et al., "Effects of melatonin and tryptophan on healing of gastric and duodenal ulcers with Helicobacter pylori infection in humans," Journal of Physiology and Pharmacology, vol. 62, no. 5, pp. 521-526, 2011.

[72] T. K. Kim, Y. S. Park, H. Baik et al., "Melatonin modulates adiponectin expression on murine colitis with sleep deprivation," World Journal of Gastroenterology, vol. 22, no. 33, pp. 7559-7568, 2016.

[73] W. W. Souba, "Glutamine and cancer," Annals of Surgery, vol. 218, no. 6, pp. 715-728, 1993.
[74] K. S. Kuhn, M. Muscaritoli, P. Wischmeyer, and P. Stehle, "Glutamine as indispensable nutrient in oncology: experimental and clinical evidence," European Journal of Nutrition, vol. 49, no. 4, pp. 197-210, 2010.

[75] M. Nakaya, Y. Xiao, X. Zhou et al., "Inflammatory T cell responses rely on amino acid transporter ASCT2 facilitation of glutamine uptake and mTORC1 kinase activation," Immunity, vol. 40, no. 5, pp. 692-705, 2014.

[76] H. Xue, A. J. D. Sufit, and P. E. Wischmeyer, "Glutamine therapy improves outcome of in vitro and in vivo experimental colitis models," Journal of Parenteral and Enteral Nutrition, vol. 35, no. 2, pp. 188-197, 2011.

[77] A. K. Akobeng, M. Elawad, and M. Gordon, "Glutamine for induction of remission in Crohn's disease," The Cochrane Database of Systematic Reviews, vol. 2, Article ID CD007348, 2016.

[78] E. Joo, S. Yamane, A. Hamasaki et al., "Enteral supplement enriched with glutamine, fiber, and oligosaccharide attenuates experimental colitis in mice," Nutrition, vol. 29, no. 3, pp. 549$555,2013$.

[79] M. Davaatseren, J.-T. Hwang, J. H. Park, M.-S. Kim, S. Wang, and M. J. Sung, "Poly- $\gamma$-glutamic acid attenuates angiogenesis and inflammation in experimental colitis," Mediators of Inflammation, vol. 2013, Article ID 982383, 8 pages, 2013.

[80] C. Bauchart-Thevret, B. Stoll, and D. G. Burrin, "Intestinal metabolism of sulfur amino acids," Nutrition Research Reviews, vol. 22, no. 2, pp. 175-187, 2009.

[81] D. G. Burrin, "New insights into sulfur amino acid function in gut health and disease," in Proceedings of the 2014 ADSA-ASASCSAS Joint Annual Meeting, vol. 45, no. 3, pp. 597-598, Kansas City, Mo, USA, 2014.

[82] E. Maroufyan, A. Kasim, G. Yong Meng et al., "Effect of dietary combination of methionine and fish oil on cellular immunity and plasma fatty acids in infectious bursal disease challenged chickens," The Scientific World Journal, vol. 2013, Article ID 531397, 9 pages, 2013.

[83] L. G. Guijarro, J. Mate, J. P. Gisbert et al., "N-acetyl-L-cysteine combined with mesalamine in the treatment of ulcerative colitis: randomized, placebo-controlled pilot study," World Journal of Gastroenterology, vol. 14, no. 18, pp. 2851-2857, 2008.

[84] H. Zhang, J. Kovacs-Nolan, T. Kodera, Y. Eto, and Y. Mine, “ $\gamma$ Glutamyl cysteine and $\gamma$-glutamyl valine inhibit TNF- $\alpha$ signaling in intestinal epithelial cells and reduce inflammation in a mouse model of colitis via allosteric activation of the calciumsensing receptor," Biochimica et Biophysica Acta-Molecular Basis of Disease, vol. 1852, no. 5, pp. 792-804, 2015.

[85] F. Santangelo, "The regulation of sulphurated amino acid junctions: fact or fiction in the field of inflammation?" Amino Acids, vol. 23, no. 4, pp. 359-365, 2002.

[86] M. Shimizu, Z. Zhao, Y. Ishimoto, and H. Satsu, "Dietary taurine attenuates dextran sulfate sodium (DSS)-induced experimental colitis in mice," Advances in Experimental Medicine and Biology, vol. 643, pp. 265-271, 2009.

[87] K. Joo, Y. Lee, D. Choi et al., "An anti-inflammatory mechanism of taurine conjugated 5-aminosalicylic acid against experimental colitis: Taurine chloramine potentiates inhibitory effect of 5 -aminosalicylic acid on IL- $1 \beta$-mediated NF $\kappa$ B activation," European Journal of Pharmacology, vol. 618, no. 1-3, pp. 91-97, 2009.

[88] M. Giriş, B. Depboylu, S. Dogru-Abbasoglu et al., "Effect of taurine on oxidative stress and apoptosis-related protein 
expression in trinitrobenzene sulphonic acid-induced colitis," Clinical and Experimental Immunology, vol. 152, no. 1, pp. 102110, 2008.

[89] J.-P. Motta, K. L. Flannigan, T. A. Agbor et al., "Hydrogen sulfide protects from colitis and restores intestinal microbiota biofilm and mucus production," Inflammatory Bowel Diseases, vol. 21, no. 5, pp. 1006-1017, 2015.

[90] M. Medani, D. Collins, N. G. Docherty, A. W. Baird, P. R. O'Connell, and D. C. Winter, "Emerging role of hydrogen sulfide in colonic physiology and pathophysiology," Inflammatory Bowel Diseases, vol. 17, no. 7, pp. 1620-1625, 2011.

[91] Z. Jin, H. Chan, J. Ning, K. Lu, and D. Ma, "The role of hydrogen sulfide in pathologies of the vital organs and its clinical application," Journal of Physiology and Pharmacology, vol. 66, no. 2, pp. 169-179, 2015.

[92] K. L. Flannigan, T. A. Agbor, J.-P. Motta et al., "Proresolution effects of hydrogen sulfide during colitis are mediated through hypoxia-inducible factor-1 $\alpha$," FASEB Journal, vol. 29, no. 4, pp. 1591-1602, 2015.

[93] A. Zandifar, S. Seifabadi, E. Zandifar et al., "Comparison of the effect of topical versus systemic L-arginine on wound healing in acute incisional diabetic rat model," Journal of Research in Medical Sciences, vol. 20, no. 3, pp. 233-238, 2015.

[94] J. J. de Lima Silva, D. G. Pompeu, N. C. Ximenes et al., "Effects of kaurenoic acid and arginine on random skin flap oxidative stress, inflammation, and cytokines in rats," Aesthetic Plastic Surgery, vol. 39, no. 6, pp. 971-977, 2015.

[95] P. Li, Y.-L. Yin, D. Li, W. S. Kim, and G. Wu, "Amino acids and immune function," The British Journal of Nutrition, vol. 98, no. 2, pp. 237-252, 2007.

[96] D. D. Rees, R. M. J. Palmer, H. F. Hodson, and S. Moncada, "A specific inhibitor of nitric oxide formation from ${ }_{L}$-arginine attenuates endothelium-dependent relaxation," British Journal of Pharmacology, vol. 96, no. 2, pp. 418-424, 1989.

[97] M. O. Taha, J. V. De Oliveira, M. Dias Borges et al., "Larginine modulates intestinal inflammation in rats submitted to mesenteric ischemia-reperfusion injury," Transplantation Proceedings, vol. 48, no. 2, pp. 512-515, 2016.

[98] S.-K. S. Hong, B. E. Maltz, L. A. Coburn et al., "Increased serum levels of L-arginine in ulcerative colitis and correlation with disease severity," Inflammatory Bowel Diseases, vol. 16, no. 1, pp. 105-111, 2010.

[99] N. P. Zwintscher, P. M. Shah, S. K. Salgar et al., "Hepatocyte growth factor, hepatocyte growth factor activator and arginine in a rat fulminant colitis model," Annals of Medicine and Surgery, vol. 7, pp. 97-103, 2016.

[100] H. S. Farghaly and R. H. Thabit, "l-arginine and aminoguanidine reduce colonic damage of acetic acid-induced colitis in rats: potential modulation of nuclear factor- $\kappa \mathrm{B} / \mathrm{p} 65$," Clinical and Experimental Pharmacology and Physiology, vol. 41, no. 10, pp. 769-779, 2014.

[101] I. Soufli, R. Toumi, H. Rafa, and C. Touil-Boukoffa, "Overview of cytokines and nitric oxide involvement in immunopathogenesis of inflammatory bowel diseases," World Journal of Gastrointestinal Pharmacology and Therapeutics, vol. 7, no. 3, pp. 353-360, 2016.

[102] I. K. Cheah and B. Halliwell, "Ergothioneine; antioxidant potential, physiological function and role in disease," Biochimica et Biophysica Acta - Molecular Basis of Disease, vol. 1822, no. 5, pp. 784-793, 2012.

[103] T. Asahi, X. Wu, H. Shimoda et al., "A mushroom-derived amino acid, ergothioneine, is a potential inhibitor of inflamma- tion-related DNA halogenation," Bioscience, Biotechnology and Biochemistry, vol. 80, no. 2, pp. 313-317, 2016. 


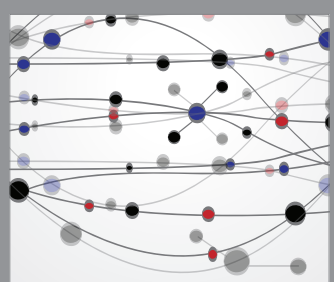

The Scientific World Journal
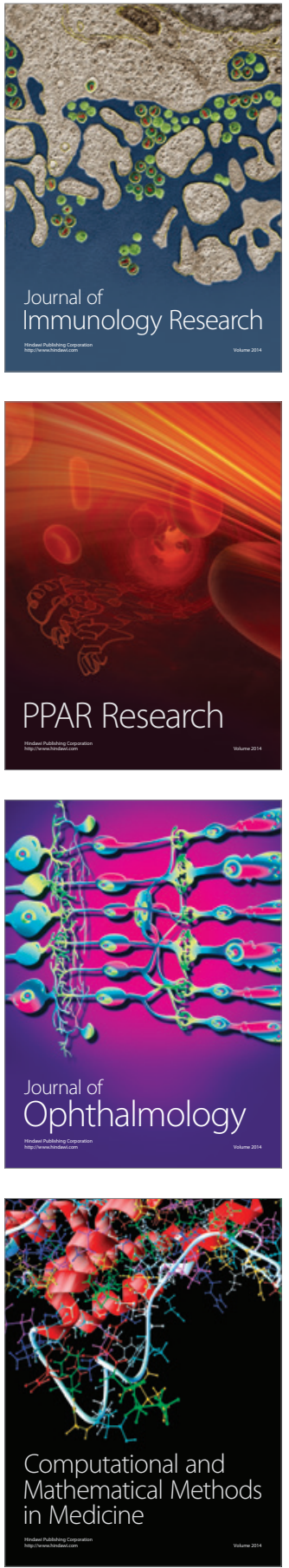

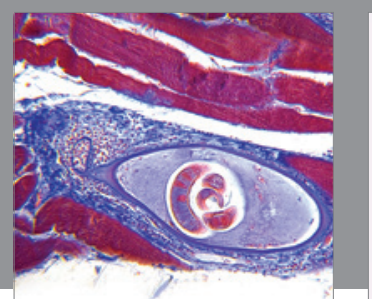

Gastroenterology Research and Practice
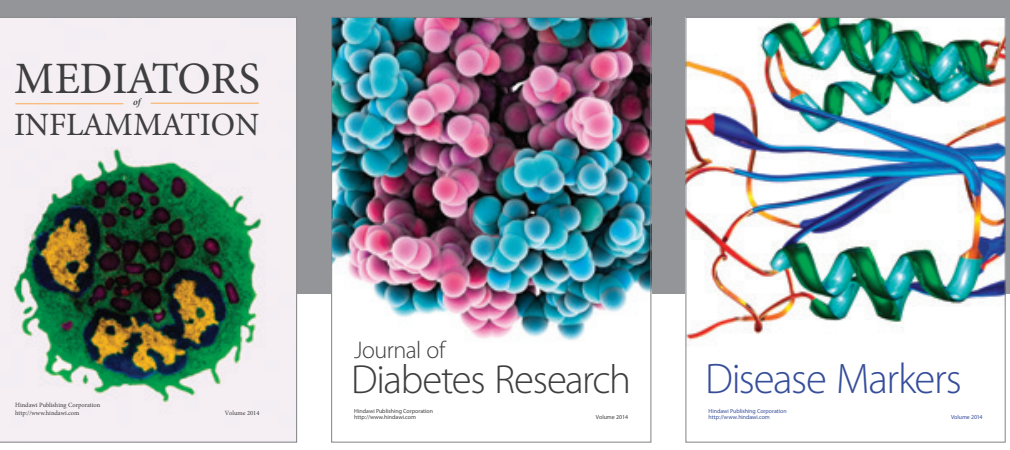

Disease Markers

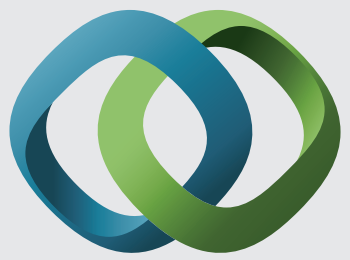

\section{Hindawi}

Submit your manuscripts at

https://www.hindawi.com
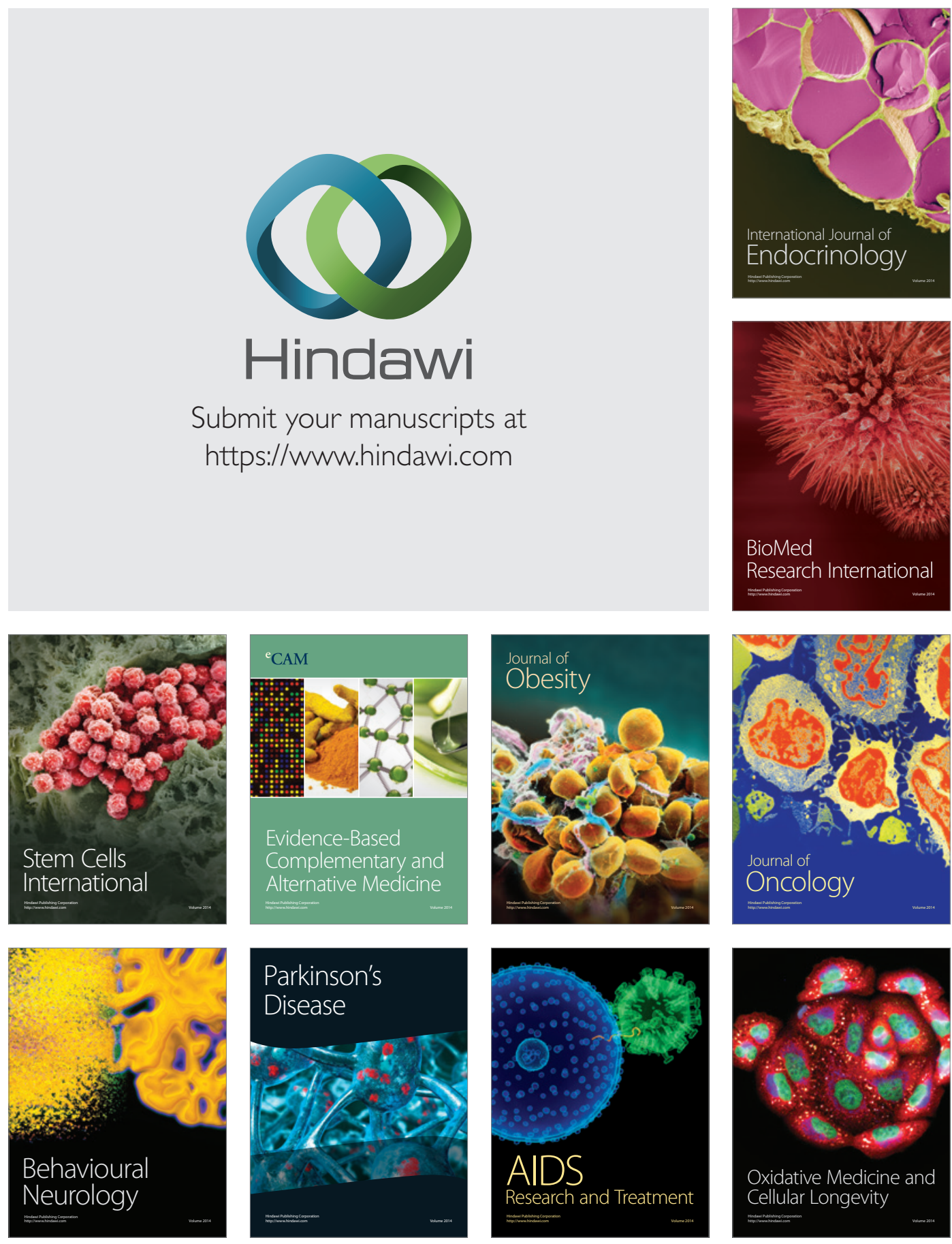